\title{
A narrativa compartilhada em jogos de RPG e sua influência na formação do leitor
}

REVISTA ELETRÔNICA CIENTÍFICA DA UERGS

Nélson Lilioso de Freitas Silveira

Universidade Estadual do Rio Grande do Sul (UERGS).

E-mail: nelson-silveira@uergs.edu.br, http://lattes.cnpq.br/7936700890600520

Magali de Moraes Menti

Universidade Estadual do Rio Grande do Sul (UERGS).

E-mail: magali-menti@uergs.edu.br http://lattes.cnpq.br/56945788|467I 054

Submetido em: I 8 ago. 2021. Aceito: 22 nov. 2021. DOI: http://dx.doi.org/I0.21674/2448-0479.73.284-292

\section{Resumo}

O presente artigo é resultante de uma pesquisa documental que apresenta o RPG como ferramenta que desperta $\circ$ interesse em literatura, especificamente a literatura dos cenários onde o jogo se passa, e cujo objetivo foi investigar a influência desse tipo de narrativa na formação do leitor. Discorre sobre o histórico do RPG e sua ascendência na construção literária de um gênero RPGístico, através de uma análise sobre o jogo de interpretação em sua conceituação, elementos e substratos mecânicos, de forma a compreender a importância do lore dentro dos cenários onde ocorre a narrativa. Verifica as dinâmicas entre os jogadores, narrador e autor através do jogo, considerando o compartilhamento da narrativa. Estabelece diferenciação entre a narrativa compartilhada e a coautoria da narrativa. Investiga o metagame e suas influências dentro da narrativa. Realiza levantamento de informações sobre as Night Witches. Desenvolve estudo de caso para verificar a influência da narrativa compartilhada na formação leitora bem como a capacidade do RPG em colaborar com a formação leitora através desse compartilhamento. Utilizamos a metodologia de pesquisa bibliográfica e estudo de caso para desenvolver uma análise epistemológica sobre o tema, investigando conceitos em sua aplicação prática. Constatamos o incentivo à formação leitora ao estimular o jogador a ler mais, sobre o jogo, o sistema, o cenário e outras informações. Destarte, ao inserir o leitor como protagonista, viabiliza aplicar o obtido na experimentação performática e lúdica das experiências literárias, o tornar contador da história e personagem daquilo que ele leu e pode estar lendo.

Palavras-chave: Ludicidade; metagame; lore; night witches.

\section{Abstract}

\section{The shared narrative in RPG games and its influence on the reader's formation}

This article is the result of a documental research which presents RPG as a tool to create interest in literature, specifically about the setting of the game and addresses the history of RPG and its influence on creating a literary genre, its objective is to seek the influence of these narratives in reader's development. This research analyses the role-playing game's concepts, and mechanics to understand the importance of the lore for the game. It verifies the dynamics between players, game master, and author, considering the shared narrative and establishing differences between shared narrative and co-authorship. It also investigates the concept of metagame and its influence within the narrative by collecting information about the Night Witches and developing a case study to verify the influence of the shared narrative in the reader's formation as well as how RPG assists the reader's formation by sharing narratives. The results of this study show that RPG encourages the reader's formation and qualifies the reading process while stimulating players to read more about the game, the system, the setting and other information. The study uses a case study and bibliographical research to develop an epistemological analysis, investigating concepts in their practical application. By inserting the reader as the protagonist, it possible to apply what has been obtained in the performative and playful expe- 
rimentation of literary experiences, making the reader the story teller and character of what they have read and may be reading.

Keywords: Playfullness; metagame; lore; night witches.

\section{Resumen}

\section{La narrativa compartida en los juegos de RPG y su influencia en la formación del lector}

Este artículo es el resultado de una investigación documental que presenta al RPG como una herramienta que despierta el interés por la literatura, específicamente la literatura sobre los escenarios donde se desarrolla el juego, y cuyo objetivo fue investigar la influencia de este tipo de narrativas en la formación del lector. Se discute la historia del RPG y su ascendencia en la construcción literaria de un género RPG, a través de un análisis del juego de rol en su conceptualización, elementos y sustratos mecánicos, con el fin de comprender la importancia del lore dentro de los escenarios donde se desarrolla la narrativa. Comprueba la dinámica entre jugadores, narrador y autor a lo largo del juego, considerando el intercambio de la narrativa. Distingue entre narrativa compartida y coautoría narrativa. Investiga el metajuego y sus influencias dentro de la narrativa. Realiza una encuesta de información sobre las Night Witches. Desarrolla un estudio de caso para verificar la influencia de la narrativa compartida en la formación del lector, así como la capacidad de los juegos de rol para colaborar con la formación del lector a través de este intercambio. Utilizamos la metodología de la investigación bibliográfica y el estudio de casos para desarrollar un análisis epistemológico sobre el tema, investigando conceptos en su aplicación práctica. Vemos el estímulo de la formación del lector al animar al jugador a leer más sobre el juego, el sistema, el escenario y otra información. Así, al insertar al lector como protagonista, permite aplicar lo obtenido en la experimentación performativa y lúdica de experiencias literarias, convirtiéndose en narrador y personaje de lo que ha leído y puede estar leyendo.

Palabras clave: Alegría; metagame; lore; night witches.

\section{Introdução}

Quando se fala na formação do leitor, constatamos que pouco se pesquisa sobre elementos de fora do âmbito acadêmico, muito embora já existam alguns estudos sobre a influência de quadrinhos, filmes e animações na produção acadêmica.

As observações encontradas sobre esses temas são limitadas ao objeto de investigação em si, e não à sua influência na formação leitora dos indivíduos que os consomem. Levantamento realizado entre os meses de novembro de 2020 a maio de 2021, no repositório de teses da CAPES e do Google Scholar, mostrou inexistir análise sobre a narrativa compartilhada em jogos de RPG e sua a influência na formação leitora, justificando o interesse na realização do presente estudo.

O ato de ler é complexo e demanda análise por si, verificamos isso nas inúmeras teorias e estudos desenvolvidos, e entendemos que sua estrutura vem sendo radicalmente afetada e modificada pela tecnologia e dinâmicas sociais pós-modernas. Desta forma, verificamos necessário tecer breve consideração sobre narrativa compartilhada em jogos de RPG de mesa, modalidade em alta mesmo fazendo uso de livros e papeis físicos num mundo digital.

Da mesma forma, compreendemos que é enriquecedor aprimorar e potencializar as ferramentas de formação leitora, em especial aquelas que possam fazer uso da literatura para instigar, provocar e atrair novos leitores ou resgatar aqueles que eventualmente se afastaram.

Partindo desses pressupostos verificamos ser necessário e oportuno desenvolver um estudo sobre esse tema englobando compartilhamento narrativo, jogos, RPG e formação do leitor, tomando como base as experiências de jogadores que possam ser provocados para uma melhor relação com a leitura. Com este enfoque realizamos pesquisa bibliográfica e um estudo de caso para compreender a influência do controle narrativo sobre a formação leitora.

Objetivamos contribuir com os processos de formação leitora através de um novo enfoque, de empoderamento do leitor sobre a narrativa e estímulo da criatividade, escolha e decisão, também intentando estimular novas práticas leitoras através de uma reformulação da recepção dos textos. 


\section{Conceito e terminologia do RPG}

A sigla RPG (que em tradução livre significa Jogo de Interpretação) originalmente surge como uma evolução de war games, especificamente dos jogos de tabuleiro que passaram a permitir uma maior personalização dos jogadores e a construção de personas as quais enfrentavam os desafios apresentados pela figura do Mestre do Jogo, vivendo as ações como personagens e não mais apenas realizando ações mecânicas de jogo. (CUPERTINO, 2008).

Em uma acepção generalista o RPG é uma contação de história jogável, na qual os personagens que participam da narrativa são interpretados pelos jogadores e suas ações são limitadas por regras mecânicas; as quais definem se a ação tomada foi um sucesso, um fracasso ou se sequer foi realizada. (CUPERTINO, 2008).

Para além da contação de história, o RPG atualmente é um jogo que possui uma narrativa viva onde se misturam elementos da literatura, do teatro e jogos. Tradicionalmente é jogado por um grupo de pelo menos três (03) pessoas, das quais um assume a figural de Metre ou Narrador (CUPERTINO, 2008).

O jogo possui dois elementos básicos: sistema e cenário. Enquanto o primeiro é o manual de mecânicas definindo regras para ações (criação de personagem, combates, recuperação de vida, construção de itens, montar, caminhar etc), o segundo é o local onde o jogo ocorre (descrição do mundo com sua mitologia, organização social, geografia, tecnologia, acontecimentos e possibilidades narrativas). (PAVÃO, 2002 apud CUPERTINO, 2008).

Importante considerar que no RPG a função do mestre não é a de contador de histórias, assemelha-se mais a figura do diretor de uma obra (seja teatral, cinematográfica ou televisionada). Embora o narrador seja o contador da história como o guia do mundo (o organizador do cenário e da dinâmica do enredo) ele divide a função de autor com os jogadores, razão pela qual o narrador não é um contador em si. (CUPERTINO, 2008).

A partir do momento que nenhum jogador tem o controle absoluto de todos os personagens, nem mesmo o narrador pois o enredo construído por ele é alterado pelas ações dos jogadores, a narrativa se torna compartilhada. O desenvolvimento da narrativa, do enredo e os desdobramentos da trama passa a ser resultado das escolhas e ações coletivas.

Como no RPG cada jogador tem controle sobre as ações de seu personagem (nem que seja apenas sobre isso), a narrativa se torna compartilhada porque o grupo divide as funções de contar a história. Neste momento verifica-se que o Narrador/Mestre é um diretor que conduz o roteiro, contando com as atuações e escolhas dos jogadores - sendo estes coautores da narrativa conforme (CUPERTINO, 2008)

Outrossim, a flexibilidade desta narrativa compartilhada (bem como sua amplitude) vai ser possibilitada a cada mudança de sistema, como fruto consequencial das gerações de Mestres/Narradores e das influências que cada novo grupo de jogadores de RPG é influenciado pelas mídias de entretenimento.

\section{A coautoria da narrativa e RPG INDIE}

Nesta modalidade a narrativa se estrutura de forma diferente da tradicional: a relação de poderes e prerrogativas no jogo é homogeneizada, pulverizando a responsabilidade e o controle sobre a história, dando ao coletivo uma atuação mais holística dentro da construção de cenário, de interação dos personagens, e até do próprio histórico do enredo trabalhado (BORGES, 2016).

O termo indie, abreviação da palavra inglesa independent e que representa uma produção autoral livre da influência do mercado, das massas e da crítica, se adequa ao conceito de liberdade do ponto de vista do controle da narrativa. Por outro lado, há quem mencione que tal característica apenas ressalta a produção de jogos independentes e sem o envolvimento de editoras (grandes ou médias), como forma de buscar um resultado mais criativo e menos comerciais não vinculados diretamente ao conceito de narrativa compartilhada. (NOGUEIRA, 20I2).

É importante considerar que entendemos haver diferença entre a ideia de narrativa compartilhada e o conceito de coautoria da narrativa, discordando da nomenclatura abordada pelos autores acima mencionados. Enquanto a primeira se refere a um compartilhamento de consequências no enredo, a segunda pressupõe uma liberdade quase total de estruturação prévia, permitindo inclusive a ausência de mediador (Mestre ou Narrador) no jogo. 
Entendemos que a narrativa compartilhada está ligada ao conceito de obra aberta de Umberto Eco (1962), no sentido de permitir ao interlocutor (jogador-leitor) assumir o controle e definir o desenvolvimento e a conclusão da narrativa - muito embora sejam preservados os elementos estruturantes da história e do enredo.

\section{A literatura no RPG e o LORE dos cenários}

Conforme já se analisou previamente, o RPG é um jogo que permite uma infinidade de narrativas e a vivência em quase qualquer enredo, sendo muito comum a adaptação de histórias e roteiros de qualquer mídia para cenários serem jogados; as adaptações de Senhor dos Anéis, Star Wars e Marvel são algumas das mais jogadas.

Entretanto, também é muito comum que sistemas de RPG sejam acompanhados de cenários próprios, muitas vezes com histórias e enredos complexos. $O$ chamado lore de um cenário é muito importante para o jogo, uma vez que ele estrutura as relações sociais, culturais e políticas do mundo onde se jogará. (CUPERTINO, 2008).

Verificamos, desta forma, que a literatura nos jogos de roleplay é mais do que um elemento marginal, passando a ser trabalhada mesmo em casos onde a realidade é reproduzida em quase sua literalidade (jogos sem elementos de magia, divindades ou tecnologia avançada). Seja num cenário fantástico ou num cenário realista, o lore será estruturado para encaixar-se com a mecânica de jogo e suas intenções. (SILVA, 2020).

Exemplos de lore oficiais e originais de jogos de RPG, Forgotten Realms, Tormenta, e A Lenda dos Cinco Anéis, possuem histórias complexas - com gerações de fatos, personagens, acontecimentos e estruturas sociais a serem conhecidas. Mesmo que seja possível aos jogadores participarem dos jogos sem conhecer a literatura do mundo jogado, a estruturação do jogo provoca a necessidade de se debruçar sobre o lore daquele cenário para viabilizar uma experiência mais rica e profícua.

Se o narrador não é necessariamente o autor, o jogador é necessariamente o personagem principal da história. Mesmo que ele a compartilhe com quem conta a história (PJ) e conduz as trilhas da narrativa, é o jogador quem a vivência como leitor do enredo e personagem da trama. Motivo pelo qual a imersão do leitor encontra um patamar mais interativo e personalíssimo na narrativa, tendo em vista que as decisões e atos definem o andamento da história (CUPERTINO, 2008).

Por isto o conhecimento da história permite ao jogador uma maior imersão quando ele domina ou conhece significativamente o lore do jogo, pois é através de seu domínio da narrativa prévia que o chamado PC pode moldar os rumos da narração da história e o desenvolvimento do enredo (SILVA, 2020).

\section{A narrativa compartilhada nos jogos de RPG}

Ao analisar os efeitos das produções culturais pós-modernas, Umberto Eco (20I6) define a ideia de obra aberta como aquela na qual $\mathrm{o}$ autor não se preocupa em estabelecer parâmetros fechados, eis que $\circ$ ato de fruição ou interpretação se dará através de um processo subjetivo.

Diferentemente do que tradicionalmente ocorre com as obras literárias, onde elementos marginais do enredo são completados pelo leitor através do processo interacionista, o caso da obra aberta permite ao receptor da mensagem participar ativamente da construção da narrativa (ECO, 2016).

Essa ideia de abertura, que permite uma cocriarão individual pelo leitor, se aproxima dos elementos definidores da metaficção - onde o receptor da mensagem participa ativamente da construção do mundo que é o cenário da obra, envolvido intelectualmente, imaginativamente e afetivamente (HUTCHEON, 1984).

Outrossim, ao conceituar Metafição, Linda Hutcheon o faz em oposição a ideia de pós-modernismo, uma vez que considera a problemática da definição que o termo impõe para incluir obras antigas (mas que se enquadram no conceito) e excluir obras contemporâneas (e que possuem uma estrutura mais tradicional): "Portanto, o termo deve denotar uma entidade literária tecnicamente definível. O 'pós' do 'pós-modernismo', assim, sugere não 'depois', mas sim uma extensão do modernismo e uma reação a ele"'

Assim, tanto obra aberta quanto metaficção estão mais vinculadas ao poder que o leitor tem sobre o enredo do que em outras características do texto, denotando que o processo de compartilhamento da narrativa é resgatado em formatos atuais através do meio pelo qual integra-se o leitor ao enredo lhe dando poder sobre a narrativa.

I So the term must denote a technically definable literary entity. The "post" of "postmodernism" would therefore suggest not "after," so much as an extension of modernism and a reaction to it." 
Essa ideia se encaixa no processo de fruição contemporânea, no qual a individualidade da experiência é um dos maiores elementos buscados e que a subjetividade da percepção requer maior maleabilidade das obras disponíveis - considerando que o leitor atual deseja participar da narrativa (SILVA, 2020).

Nesse cenário, a discussão terminológica que Hutcheon enfrenta ao justificar a escolha do termo metaficção é compreendida. Ao nos depararmos com a confusão entre o efeito (compartilhamento narrativo) e sua incidência, a primeira reação é contextualizar isso como um efeito pós-moderno, um sintoma da época - isto, porque era digital sinalizava perda de espaço para a literatura, na medida em que sua formatação tradicional não se mostrava atraente face às novas formas de entretenimento e interação das novas gerações.

Há exemplos de conteúdos interativos na internet, usando textos e a construção de narrativas, permitindo a participação do leitor como coautor da narrativa quando escolhas tomadas pelo público influenciam o desenvolvimento do enredo. Votações, opções de diferentes caminhos na história, incluindo finais alternativos que podem ser escolhidos, demonstram que a obra aberta é um fenômeno do século XXI.

Mais recentemente, exemplos como o do quadrinho virtual Homestuck mostraram o poder da narrativa compartilhada e sua influência no público. A multimodalidade das plataformas onde transcorria a narrativa contava com textos, hiperlinks, GIFS, animações com as quais os leitores poderiam participar, escolher e influenciar no desenvolvimento do enredo e nas modificações na história (ALMEIDA, 2019).

Como menciona Almeida (20।9), Homestuck se tratou de uma obra aberta pela não conclusão de seu enredo tanto quanto a possibilidade de modificação através da interação com leitor, possibilitando uma miríade de interpretações nos termos do conceito proferido por Umberto Eco em sua Obra Aberta (2016).

Outrossim, ainda que os jogos eletrônicos e redes sociais tenham assumido grande relevância na construção das narrativas neste novo milênio, cumprindo um papel que tradicionalmente era da literatura, sua limitação ainda esbarra na capacidade tecnológica. Mesmo com opções muito avançadas e flexíveis, ainda há uma delimitação do que o leitor pode escolher e não uma liberdade plena de compartilhamento narrativo (ALMEIDA, 2019).

De toda a forma, a narrativa destas novas mídias leva ao questionamento sobre a influência e a inspiração literária na construção das experiências, aventuras e na formação das gerações pós-analógicas, demonstrando a amplitude das possibilidades quanto à possibilidade de interação maior entre leitor-obra (SILVA, 2020).

E isto nos leva ao Role Plaing Game (RPG), "jogo de interpretação", em seu formato conhecido como RPG de mesa, como veículo de imersão plena do leitor na obra e sua inserção como coautor da narrativa na medida em que atua para o desenvolvimento da narrativa de forma plena através das suas escolhas e interpretação de personagem (SILVA, 2020).

O referido jogo permite uma leitura e estudo sobre o processo de influência da literatura nas narrativas da era digital; uma vez que o jogo se mostra um amálgama da literatura tradicional com elementos pós-modernos de interação, podendo criar uma relação mais personalista entre os leitores do jogo e a narrativa que é construída através dele (SILVA, 2020).

No RPG o leitor é também jogador e coautor da narrativa, uma vez que pode estabelecer, alterar ou definir marcos estruturantes da narrativa, decidindo os desdobramentos das cenas, a resolução dos conflitos e $\circ$ destino da história. Trata-se de um jogo em que uma narrativa pré-construída é vivenciada e definida através de outros elementos alheios à decisão do autor original (HUTCHEON, 1984).

Considera-se o jogador capaz de estabelecer marcos da narrativa quando constrói a história, características e personalidade do personagem; de forma que, mesmo não tendo influência na construção do mundo, sua participação na criação do personagem influi em um elemento estruturante da narrativa (SILVA, 2020).

Por sua vez a alteração da narrativa ocorre quando o personagem criado pelo jogador se insere num mundo pré-estabelecido, com personagens criadas pelo autor daquele cenário e atuando em tramas que foram concebidas sem a existência daquela personagem criada pelo jogador, sendo um novo marco que definirá parte das decisões, escolhas e rumos de uma história pensada sem aquele indivíduo (SILVA, 2020).

Também no jogo de RPG verifica-se a possibilidade de uma projeção desconstruída da imagem do jogador, facilitando que o leitor se torne e atue como diferentes personas dentro da narrativa, além de abrir um infinito leque de possibilidades para o andamento da história, percepção da leitura e a experimentação dos variados enredos viabilizados pelo jogo. Através desta liberdade o jogador pode moldar de forma livre toda a narrativa e os resultados da história (SILVA, 2020). 
Mesmo que se considere a diferença de papel entre o jogador e o narrador, figuras que têm funções diversas dentro do jogo e da narrativa, ambos atuam como coautores na medida em que mudam o desenvolvimento da história e a modificação do enredo (SILVA, 2020).

É importante relembrar que a narrativa é compartilhada a partir do momento em que nenhum jogador tem o controle absoluto de todos os personagens. Nem mesmo o narrador, posto que mesmo o enredo construído por ele pode ser alterado pelas ações dos jogadores. Ali a metaficção se entrelaça com a obra aberta, criando uma rede de reações a cada ação ou decisão feita no jogo.

Como no RPG cada jogador tem controle sobre as ações de sua personagem (nem que seja apenas sobre isso), a narrativa se torna compartilhada porque o grupo divide as funções de contar a história. Neste momento verifica-se que o Narrador/Mestre é um diretor que conduz o roteiro, contando com as atuações e escolhas dos jogadores - sendo estes coautores da narrativa.

\section{As Night Witches}

Para investigar os questionamentos lançados realizamos um estudo de caso em uma aventura do jogo Night Witches, subsidiado por pesquisa dos fatos históricos que embasaram a criação de padrões para verificar a proximidade entre as ações realizadas e os comportamentos das personagens nas sessões de RPG analisadas.

$O$ jogo se desenvolveu em um conjunto de nove sessões das quais analisaremos as duas primeiras, identificadas cada uma como sessão zero (episódio 0) e sessão um (episódio I), cada uma com duração média de três horas de gravação disponível no canal Flexa Mágica no site Youtube.

Todos os nomes referidos nesse estudo de caso são das personagens dos jogadores, sendo elas identificadas com a sigla PJ (personagem jogador), ou dos personagens da história que são controlados pelo narrador (PNJ, sigla de Personagem Não Jogador).

Como fonte primária da pesquisa foi consultado o livro As Bruxas da Noite (2019), de Ritanna Armeni, onde foi possível analisar os fatos históricos através de entrevistas com uma das aviadoras e levantamento de documentos históricos. Também foram consultados documentários disponíveis no Youtube que tratam do tema, como Chronicles of Courage: Night Witches (NBC News Learn), The Soviet Night Witches of World War Two (BBC Reel), e The Night Witch: The story of Nadia, Soviet Bomber Pilot (The New York Times).

Todos os materiais serviram de base para construir um perfil das aviadoras e traçar elementos que estruturassem as comparações realizadas, de forma que fosse possível estabelecer um padrão repetido e, com isto, verificar se o RPG levou os jogadores a qualificar sua formação leitora através da narrativa compartilhada.

\section{Tabela I - Perguntas desenvolvidas para orientar a pesquisa}

I) Respeito pela hierarquia militar e obediência ao comando.

2) Dedicação à causa de libertação do território da URSS dos invasores Nazistas.

3) Utilização de aeronaves defasadas com recursos limitados para missões de risco.

4) Animosidade com o batalhão masculino e o preconceito de gênero sofrido pelas aviadoras.

5) Camaradagem e conflitos entre as aviadoras.

Fonte: Silveira, Menti, UERGS (202I).

A coluna dos comportamentos representa as perguntas (critérios norteadores), a coluna das Aviadoras descreve as respostas obtidas através da pesquisa bibliográfica, enquanto que a coluna das personagens representa as respostas colhidas através da análise das sessões, e, por fim, a coluna do Padrão replicado busca verificar quais comportamentos das personagens foram similares ou diferentes ao das aviadoras reais. 


\begin{tabular}{|c|c|}
\hline COMPORTAMENTOS & AVIADORAS \\
\hline $\begin{array}{l}\text { Respeito pela hierarquia militar } \\
\text { e obediência ao comando. }\end{array}$ & $\begin{array}{l}\text { São inúmeros os } \\
\text { relatos de obediência } \\
\text { e respeito, havendo } \\
\text { poucas menções formais } \\
\text { a qualquer mínima } \\
\text { postura insubordinada. }\end{array}$ \\
\hline $\begin{array}{c}\text { Dedicação à causa de libertação } \\
\text { do território da URSS dos } \\
\text { invasores Nazistas. }\end{array}$ & $\begin{array}{c}\text { O mote principal das } \\
\text { entrevistas e pesquisas } \\
\text { foi a dedicação plena } \\
\text { das aviadoras à causa e } \\
\text { ao enfrentamento aos } \\
\text { invasores. }\end{array}$ \\
\hline $\begin{array}{c}\text { Utilização de aeronaves } \\
\text { defasadas com recursos } \\
\text { limitados para missões de risco. }\end{array}$ & $\begin{array}{l}\text { O maior recurso das } \\
\text { Bruxas era o silêncio } \\
\text { e a flexibilidade de } \\
\text { movimentos que os } \\
\text { aviões, antigos e frágeis, } \\
\text { permitiam frente a } \\
\text { estrutura avançada e } \\
\text { poderosa do exército } \\
\text { invasor. }\end{array}$ \\
\hline
\end{tabular}

No livro Base

fica evidenciada

a animosidade, principalmente quando a entrevistada deixa claro que não haviam homens no batalhão, fato que se acresce aos relatos de discriminação e desproporção no tratamento recebido pelas aviadoras.

Os relatos deixam claro a rotina de conflitos entre as aviadoras, acirrados pela situação extrema que viviam e pela precariedade de recursos, mas também deixam claro que a camaradagem era em muitas das situações o meio de resolver tais conflitos.

\section{PERSONAGENS}

Irina e Lydia

demonstravam respeito, enquanto Olga alternava críticas sutis e obediência por temor, e Margaret possuía um comportamento de enfrentamento.

Todas possuíam em níveis, ficando claro que Irina e Margaret eram as mais dedicadas - cada uma por suas próprias razões.

Todas estavam limitadas aos parcos meios disponíveis, porém algumas atitudes de Margaret permitiram acesso a melhores recursos.

Desde o começo da narrativa ficava claro o desdém sofrido pelas personagens, representado também na inferioridade dos recursos em comparação com os disponíveis ao batalhão masculino.

\section{Muitos dos conflitos} tiveram sua origem justamente na situação de convivência das personagens, seja entre si ou com as PNJ, ao passo que várias das resoluções foram desenvolvidas através da camaradagem praticada por elas.

\section{PADRÃO REPLICADO}

Irina e Margaret (PJ) reproduzem mais fielmente os comportamentos, porém a circunstância de leitura do livro base do jogo também permitiu às demais personagens uma base significativa de proximidade.

Irina reproduz com bastante fidelidade os ideais, motivações e elementos das aviadoras, em grande parte por sua leitura do livro base da pesquisa diferencial das demais PJ.

Todas as jogadoras têm conhecimento da realidade e por isso atuam no sentido de usar o que está a mão, porém Lydia e Olga (PJ) são as que mais demonstram proatividade em resolver situações com as limitações que o cenário e o sistema viabilizam.

Olga e Margaret (PJ) desde o começo demonstram a maior animosidade com a situação discriminatória que as aviadoras sofrem, atuando diretamente em questionar, enfrentar e causando os mais relevantes conflitos por conta da circunstância especialmente diante da invasão ao espaço aéreo do batalhão masculino.

Todas as jogadoras desempenham condutas que se encaixam diretamente com o padrão, replicando quase integralmente o perfil das aviadoras conforme $o$ material de referência. Em especial as PJ Olga e Margaret, respectivamente na cena com a aviadora (PNJ) que cometeu suicídio e com as situações decorrentes do teste de voo fracassado.

Fonte: Silveira e Menti (202I).

Todas as três aviadoras que serviram de base para o padrão estabelecido reproduziram os comportamentos dentro dos cinco (05) critérios, outrossim é salutar deixar claro que cada uma delas desempenhou uma postura pessoal única e os elementos colhidos representam uma generalização temática para o estudo desenvolvido.

\section{Considerações finais}

Ao longo deste trabalho tivemos oportunidade de compreender mais profundamente a realidade da formação leitora e conectar esses elementos teóricos com a aplicação prática, através de uma ferramenta que possibilitasse despertasse $o$ interesse do leitor pela literatura. Com esse objetivo traçamos um fenômeno a ser estudado para responder se a narrativa compartilhada desperta o interesse pela literatura através dos jogos de RPG. 
Realizamos pesquisa bibliográfica e desenvolvermos um estudo de caso para responder a esse questionamento, estabelecendo objetivos a serem enfrentados para, desta forma, obter uma resposta sobre o tema investigado. Através do levantamento de dados bibliográficos traçamos roteiro explicitando os pontos relevantes da matéria, explicando o RPG e submergindo na realidade do jogo, de forma a nos ambientar no objeto pesquisado e desenvolver a percepção necessária à resolução da pergunta de pesquisa.

Importante considerar que a análise realizada buscou seguir um caminho diverso de outros trabalhos, que abordavam o RPG superficialmente pois entendemos que a pesquisa exigia nova abordagem. Por isso decidimos ir além, referenciando o que outros autores já enfrentaram, mas focando em outros elementos relevantes.

Entendemos que para um trabalho sobre formação leitora o RPG possui um interesse maior quando se avalia sua oralidade associada com a autoria, por isso o foco na temática de cenários, lore e compartilhamento da narrativa: são nesses pontos que verificamos a maior relevância do jogo de roleplay para a literatura.

Possibilitar que o leitor crie seu personagem para viver no mundo de seu livro preferido é uma ferramenta que estimula a formação leitora, e tivemos a oportunidade de verificar isto quando analisamos o caso estudado e como o interesse foi despertado pela possibilidade de viver (ainda que de maneira encenada) uma realidade e contexto históricos.

Diante disto foi que através da pesquisa bibliográfica respondemos os objetivos específicos ao analisar o lore dos jogos de RPG, constatando o peso da literatura dos jogos para a interpretação e para o próprio jogo - especialmente considerando os exemplos nos quais deter conhecimento sobre o mundo do jogo é essencial para jogar.

Os exemplos Lobisomem: O Apocalipse e Tormenta são demonstrações da forma como a literatura do RPG impacta os jogadores, os quais necessitam de vários livros para posicionar o jogador dentro do momento e do contexto do Jogo. A quantidade de suplementos, livros e textos que os jogadores de RPG precisam para jogar mostra a sua relevância para a formação leitora.

E não apensa isto, o exemplo do RPG brasileiro Tormenta vai além quando exporta a literatura do cenário para fora do próprio jogo, tendo sido escritos romances baseados naquele mundo onde ocorrem os jogos e tendo os personagens desse cenário em produções literárias para além do RPG.

Desta forma, quando chegamos ao estudo de caso temos elementos mais do que suficientes para analisar as sessões de jogo escolhidas e depreender, dai, que efetivamente o RPG pode despertar o interesse pela literatura através da narrativa compartilhada dentro do jogo.

Pudemos constatar que a literatura influencia na atuação do jogador de RPG e que a narrativa compartiIhada instiga o interesse pela literatura do jogo ao possibilitar uma maior imersão e maior leque de escolhas para os jogadores.

Nossa leitura sobre os resultados obtidos deixa claro que o jogo de RPG provocou, instigou e fomentou o interesse pela leitura, no momento em que os jogadores verificaram que munidos de maiores informações poderiam controlar mais a narrativa e terem melhores resultados para seus personagens.

Aliado a isto, o interesse pelo cenário também se provou um elemento que incentiva a leitura, uma vez que o interesse ou o gosto pelos elementos do local onde se passa o jogo também serve como catalisador para que o leitor busque maiores informações. Gostar de uma determinada temática cultural ou histórica mostra-se uma razão que leve os jogadores a procurar novas fontes de informação sobre ela, e, assim, ler mais sobre o tema.

Constatamos efetivamente que o RPG, através da narrativa compartilhada, incentiva a formação leitora e qualifica o processo de leitura quando estimula, incentiva e provoca o jogador a ler mais - sobre o jogo, $\circ$ sistema, o cenário e outras informações que acabam surgindo.

Ficamos satisfeitos com o resultado, outrossim compreendemos que a limitação causada pela pandemia do Covid-19, e até pela curta duração do curso de especialização, impossibilitou uma pesquisa mais ampla sobre o tema.

Contudo, a temática se mostrou interessante e suscetível de maiores digressões, especialmente considerando o tema de que muitos jogadores de RPG são leitores assíduos das produções e não leem mais nenhum outro tipo de literatura. Acreditamos que o próximo passo será investigar como o RPG pode ser a primeira, ou única, fonte de leitura de muitos jogadores; sendo, desta forma, mecanismo para qualificar a formação leitora. 


\section{Referências}

ALMEIDA, Maiara Alvim de. Leitores e autores na era da web 2.0 : webcomics, narrativas hipertextuais e participação. 2019. Tese (doutorado) - Universidade Federal de Juiz de Fora, Faculdade de Letras. Programa de Pós-Graduação em Estudos Literários, 2019.

MALKIE. Aventurandos: as bruxas da noite. 2017. As Bruxas da Noite. Disponível em: < https://aventurandose.wordpress.com/2017/03/09/as-bruxas-da-noite/>. Acesso em: 19 abr. 2021.

BORGES, Pedro. A narrativa compartilhada. 2015 Disponível em: $<$ http://cronicasRPG.com.br $/$ ?p $=$ I 726 $>$. Acesso em: 19 nov. 2020.

CUPERTINO, Edson Ribeiro. Vamos jogar RPG? Diálogos com a literatura, o leitor e a autoria. 2008. I32f. Dissertação (mestrado) - Universidade de São Paulo, Faculdade de Letras. Programa de Pós-Graduação em Estudos Comparados de Literaturas de Língua Portuguesa, 2008.

FREIRE, Paulo Freire. A Importância do Ato de Ler: em três artigos que se completam. 23 ed. São Paulo: Cortez, 1989.

HUTCHEON, Linda. Narcissistic Narrative: the metafictional paradox. New York: Methuen, 1984.

MUNARI, Ana Cláudia. Literatura e internet, Semana de Letras, O cotidiano das letras: Anais. org. Jocelyne Bocchese [et al.], FALE/PUCRS. Porto Alegre: EDIPUCRS, $20 \mathrm{I}$ I.

RODRIGUES, Vladimir Wanderley de Lima. Elementos constitutivos da narrativa análise do corpus de uma narrativa de RPG. 2018. 95f. Dissertação (Mestrado em Estudos da Linguagem) - Centro de Ciências Humanas, Letras e Artes, Universidade Federal do Rio Grande do Norte, Natal, 2018.

SILVA, Ulissivaldo Caetano Costa da. Criação de narrativas mediadas pelo RPG solo: contributo para o desenvolvimento da competência escritora de alunos do ensino fundamental. 2020. I39f. Dissertação (Mestrado Profissional em Letras) - PROFLETRAS, Universidade Federal da Paraíba (UFPB) - Mamanguape-PB. 2020. 